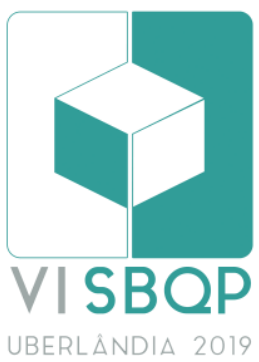

\title{
AVALIAÇÃO E ADEQUAÇÃO FíSICA DE UMA ÁREA DE PRÁTICA ESPORTIVA NA PARAÍBA, BRASIL
}

\author{
SOUSA, Francisco Judivan Celestino de \\ Instituto Federal de Educação, Ciência e Tecnologia da Paraíba (IFPB), campus \\ Cajazeiras, e-mail: fjudivan.op@hotmail.com \\ NOGUEIRA, Thacyla Milena Plácido \\ Instituto Federal de Educação, Ciência e Tecnologia da Paraíba (IFPB), campus \\ Cajazeiras, e-mail: milena.thacyla@gmail.com \\ MELO, Tássia dos Anjos Tenório de \\ Universidade Federal da Paraíba (UFPB), campus Areia, e-mail: \\ melo.tassia@yahoo.com.br
}

\begin{abstract}
RESUMO
Em uma sociedade onde a busca por equidade é tão debatida, é de responsabilidade dos profissionais da construção civil levar tal conceito a uma classe totalmente esquecida: a dos deficientes físicos. O presente trabalho é resultado de um projeto de Iniciação Científica já finalizado do IFPB e teve como objetivo fazer um levantamento e estudo acerca do Parque Aquático do Instituto Federal da Paraíba, Brasil, analisando não conformidades técnicas para o uso de pessoas com deficiência física ou mobilidade reduzida. A avaliação dos ambientes foi realizada através da metodologia da Avaliação Pós-Ocupação (APO) e complementada com os princípios do Desenho Universal, a fim de analisar a edificação com base nas recomendações da Norma Brasileira de Acessibilidade, NBR 9050/2015. Inicialmente, com o auxílio de um checklist, o ambiente foi avaliado e foram identificas diversas situações que estão em desconformidade com a NBR 9050/2015. Posteriormente foram elaborados e aplicados questionários junto àqueles afetados diretamente pela falta de acessibilidade física no Parque Aquático, bem como com as pessoas e profissionais que convivem constantemente com essas pessoas. Após aplicação dos questionários, as informações foram utilizadas para subsidiar, juntamente com o parecer técnico, as propostas de adequação dos espaços esportivos, segundo a NBR 9050/2015.
\end{abstract}

Palavras-chave: Acessibilidade Física, Normatização, Esportes, Inclusão.

\begin{abstract}
In a society where the search for equity is so debated, it is the responsibility of construction professionals to bring such concept to a class that is totally forgotten: the disabled. The present work is a result of a project of Scientific Initiation already finalized of IFPB and had as objective to make a survey and study about the Water Park of the Federal Institute of Paraíba, Brazil, analyzing technical nonconformities for the use of people with physical disability or mobility reduced. The evaluation of the environments was carried out through the methodology of the Post-Occupancy Evaluation (POE) and complemented with the principles of Universal Design, in order to analyze the building based on the recommendations of the Brazilian Standard of Accessibility, NBR 9050/2015. Initially, with the help of a checklist, the environment was evaluated and several situations were identified that are in disagreement with NBR 9050/2015. Subsequently, questionnaires were prepared and applied to those directly affected by the lack of physical accessibility in the water park, as well as to the people and professionals who live with these people constantly. After applying the questionnaires, the information was used to subsidize,
\end{abstract}

SOUSA, F. J. C.; NOGUEIRA, T. M. P; MELO, T. A. T. Avaliação e adequação física de uma área de prática esportiva na Paraíba, Brasil. In: SIMPÓSIO BRASILEIRO DE QUALIDADE DO PROJETO NO AMBIENTE CONSTRUÍDO, 6., 2019, Uberlândia. Anais... Uberlândia: PPGAU/FAUeD/UFU, 2019. p. $1112-1123$. DOI https://doi.org/10.14393/sbqp19101. 
together with the technical opinion, the proposals for the adaptation of the sports spaces, according to NBR 9050/2015.

Keywords: Physical Accessibility, Standardization Instructions, Sports, Inclusion.

\section{INTRODUÇÃO}

A Norma Brasileira NBR 9050 (ABNT, 2015) define acessibilidade como a possibilidade e condição de alcance, percepção e entendimento para utilização, com segurança e autonomia, de espaços, equipamentos, transporte, informação, entre outros, por pessoa com deficiência ou mobilidade reduzida.

Felizmente nos últimos anos, o tema acessibilidade vem ganhando destaque em virtude do fato de que essa porção significativa da população brasileira conquista seu espaço devido à criação de legislações, regulamentações e ações governamentais, que proporcionam, asseguram e incentivam a relevante participação, integração e inclusão (educacional, digital, social, cultural, econômica, etc.) das pessoas deficientes na sociedade. Logo, a garantia de direitos, como saúde, educação, emprego e moradia, tornou-se ideais a serem alcançados.

Em relação à legislação vigente voltada para o tema, destaca-se a Lei Brasileira de Inclusão da Pessoa com Deficiência (Estatuto da Pessoa com Deficiência), Lei $N^{0}$ 13.146/2015. Seu conteúdo assegura e promove, em condições de igualdade, o exercício dos direitos e das liberdades fundamentais por pessoa com deficiência, visando à sua inclusão social e cidadania.

Como ressalta Barrozo et al. (2012), a acessibilidade não é somente a autonomia em utilizar-se de um ambiente, englobando o espaço físico, mobiliário e equipamentos, mas de participar ativamente das relações no meio social desenvolvidas ali. Na promoção da inclusão social, o esporte se apresenta como uma ferramenta com grande potencial includente.

As atividades físicas, além dos benefícios orgânicos, contribuem para a promoção da independência e desenvolvimento de aspectos psicológicos positivos, como o aumento do bom humor, empatia, redução do estresse e incentivar a integração social do indivíduo (CORDEIRO, 2010; ZUCHETTO, 2002).

Diante desse contexto, é preciso conceber, em ambientes escolares, áreas de práticas esportivas que sejam inclusivas e que possibilitem não só o acesso físico, mas também a participação e integração de todas as pessoas com alguma deficiência.

É nesse contexto que a etapa final deste trabalho apresenta uma proposta de projeto de adequação de um Parque Aquático, ambiente de prática esportiva do Instituto Federal de Educação, Ciência e Tecnologia da Paraíba IFPB, campus Cajazeiras, sertão paraibano, a partir do cruzamento das informações referentes ao diagnóstico técnico e questionários aplicados.

\section{REVISÃO BIBLIOGRÁFICA}

A fim de proporcionar a concepção de projetos de ambientes adequados para as pessoas com deficiência ou mobilidade reduzida algumas 
metodologias e abordagens podem ser adotadas, como os conceitos e princípios do Desenho Universal, Avaliação Pós-Ocupação, entre outros.

Segundo Carletto e Cambiaghi (2007), o Desenho Universal é definido como a concepção de produtos e ambientes para serem usados por todos, de forma totalmente plena, sem necessidade de adaptações ou alterações para pessoas com deficiência. O objetivo do conceito é fazer com que qualquer ambiente ou produto possa ser alcançado, manipulado e utilizado, independentemente do tamanho do corpo do indivíduo, sua postura, mobilidade, idade ou qualquer outra característica pessoal.

Quanto aos benefícios sociais trazidos pela concepção de ambientes e produtos universais, Souza e Post (2016) argumentam que o Desenho Universal não somente proporciona a adequação de espaços para serem usados pelas pessoas, mas contribui para trazer essas pessoas para o convívio social e coletivo, reintegrando-as à sociedade.

A avaliação pós-ocupação (APO) é um processo para avaliar o desempenho de uma edificação depois de ocupada. É uma metodologia fundamentada na ideia de que o melhor estado do ambiente será construído mediante a consulta daqueles que o ocuparão, de forma a entender as suas necessidades. As informações são coletadas dos usuários mediante o uso de questionários, entrevistas, sites designados para tal, além de observações. 0 aprendizado desse processo irá guiar o profissional em decisões acerca de projetos futuros (FEDERAL FACILITIES COUNCIL, 2001).

Segundo Ornstein (2017), o processo de concepção, execução e uso dos ambientes construídos tem sua metodologia totalmente transformada com a inserção da APO. Antes, um processo de etapas que se sequenciam, executadas numa lógica linear e convencional, agora transformado em um processo onde a comunicação ambiente concebido com a concepção inicial é visada, de maneira a realimentar o processo com informações, promovendo melhorias e evitando repetições de equívocos.

De acordo com Preiser (1995), dentre os benefícios da APO destacam-se: melhoria do desempenho da edificação em termos de segurança, funcionalidade, eficiência e satisfação social, cultural e psicológica; redução dos custos de manutenção e operação das instalações durante a vida útil da edificação. Todos esses benefícios são alcançados mediante a confluência do feedback dos usuários e de um conhecimento técnico especializado.

Apesar de todos os benefícios, a metodologia APO não é muito adotada em organizações e instituições. A principal barreira seria a própria natureza da metodologia, a qual expõe não somente os acertos, mas também os erros do objeto avaliado (FEDERAL FACILITIES COUNCIL, 2001).

Este projeto foi idealizado com o propósito de contribuir para a análise e conformação dos ambientes de práticas esportivas do IFPB/Cajazeiras, mediante análise técnica da edificação e proposição de projetos de acessibilidade, possibilitando a integração e participação das pessoas com deficiência em práticas esportivas. 


\section{METODOLOGIA}

A pesquisa apresentou como estudo de caso o Parque Aquático do IFPB/Cajazeiras. Neste trabalho, essa área esportiva foi avaliada tendo como principal referencial a NBR 9050 (ABNT, 2015) e também como ferramenta complementar de avaliação normas afins (NBR 14718/2001, NBR 9077/2001 e NBR 16537/2016) e os princípios do Desenho Universal, sendo os principais destacados pelos pesquisadores: inteligibilidade - fácil compreensão -, seguridade - tolerante ao erro - e abrangente - apropriado para todos.

Foram realizados levantamentos físico e fotográfico in loco, com o auxílio de um checklist, trena a laser e câmeras. O levantamento fotográfico foi realizado em horário que não havia nenhuma atividade prevista no ambiente esportivo, a fim de garantir imagens que expusesse claramente as não conformidades, segundo a NBR 9050/2015.

O checklist utilizado no levantamento físico foi baseado no material "Acessibilidade: projetando e Construindo Cidadania" (MP/RN,2009), que contempla critérios e parâmetros técnicos de acessibilidade. Assim, o checklist foi estruturado em três aspectos:

- Acessos: piso, rotas de fuga, rampas e escadas, acesso à piscina;

- Circulação interna (corredores, portas e janelas) e externa (calçadas e ligação entre os ambientes esportivos e demais áreas da instituição);

- Mobiliários: assentos, banheiros e vestiários.

As informações colhidas através do checklist deram origem a um diagnóstico técnico da edificação, resultando no disposto no Quadro 1, denominado Quadro de Soluções. Nesse quadro são apresentados, resumidamente, os ambientes, os problemas identificados em cada ambiente e as soluções propostas. As soluções identificadas no quadro foram identificadas no projeto de acessibilidade, em software CAD.

Com o intuito de observar critérios qualitativos de utilização individual do espaço esportivo por usuários e não somente aspectos técnicos e normativos da acessibilidade física, foram aplicados questionários estruturados. Os questionários evidenciam aspectos comportamentais e perceptivos dos deficientes físicos, abordando questões como: o incentivo às práticas esportivas por parte de professores/amigos, a função da Instituição em proporcionar o direito à inclusão, as experiências dos deficientes em práticas esportivas e as principais dificuldades encontradas.

Segundo Marconi e Lakatos (2004), o uso da metodologia qualitativa, através da aplicação dos questionários, possibilitará o contato direto com o grupo de indivíduos relevantes do estudo, permitindo a obtenção de informações essenciais para atingir o objetivo geral do projeto.

As respostas provenientes dos questionários estão dispostas no Quadro 2 Quadro de Interpretação das Entrevistas. Esse quadro converte a visão das respostas dadas pelos entrevistados em intervenções técnicas e recomendações institucionais.

O projeto de acessibilidade para o Parque Aquático foi resultado da confluência do Diagnóstico, do Quadro de Interpretações e das diretrizes técnicas fornecidas pela NBR 9050/2015. 


\section{RESULTADOS E DISCUSSÃO}

O Parque Aquático (Figura 1) é constituído por estacionamento, arquibancada, área externa de circulação, piscina e um prédio de apoio, composto por área de banho, sala do professor, casa de máquinas, vestiários masculino e feminino.

Todas as indicações de itens normativos descritas nessa seção do trabalho fazem menção à NBR 9050 (ABNT, 2015).

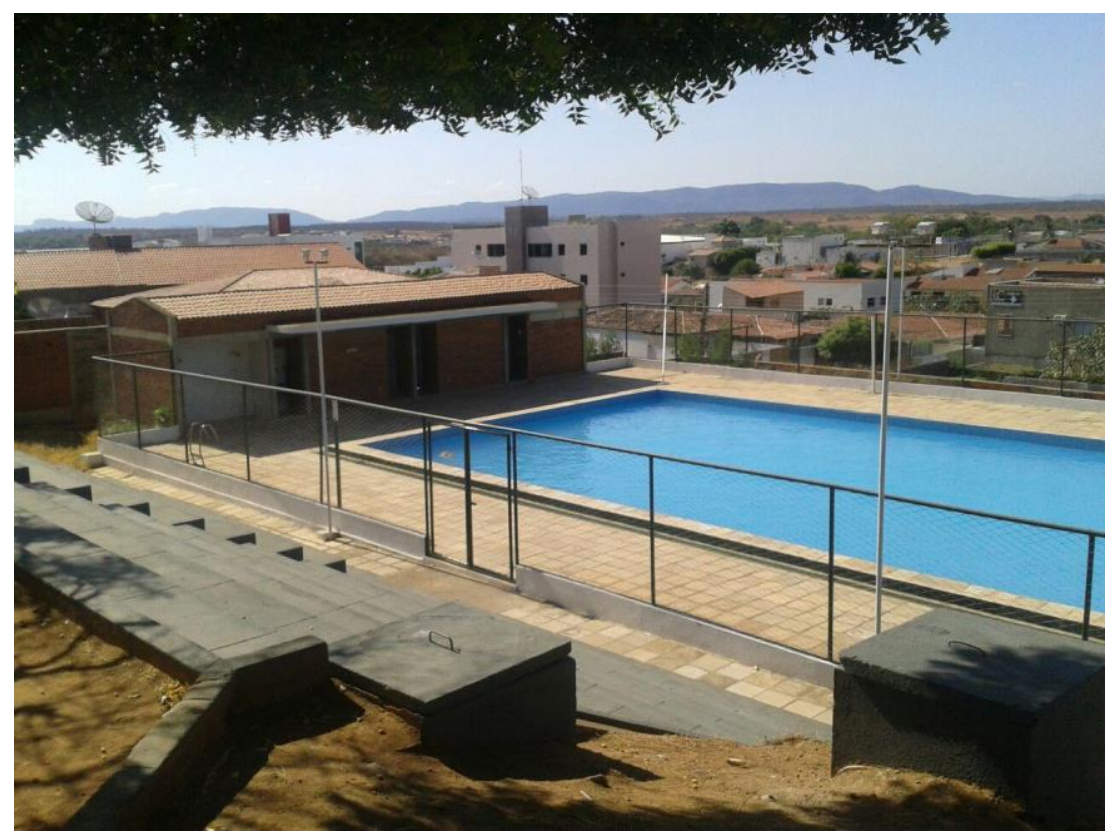

Figura 1 - Parque Aquático Fonte: Autores (2017)

\subsection{Acessos}

O estacionamento não possui distinção entre vagas preferenciais (destinadas a pessoas com deficiência, mobilidade reduzida e idosos) e as demais. A rampa que interliga o estacionamento ao Parque Aquático não garante um deslocamento autônomo e seguro, pois sua inclinação é superior a 8,33\%, o piso é trepidante e também não há elementos de segurança - corrimão e guarda-corpo (Figura 2).
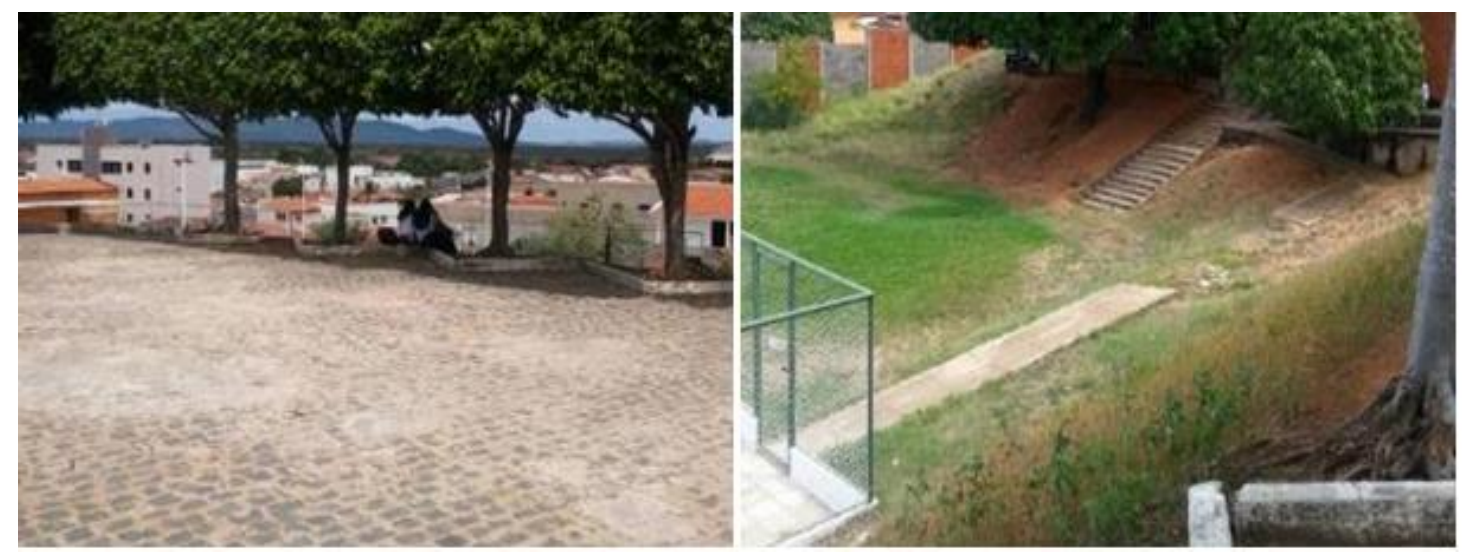

Figura 2 - Estacionamento e rampa de acesso ao Parque Aquático, respectivamente Fonte: Autores (2017) 
A circulação de acesso à arquibancada do Parque Aquático possui largura de $0,85 \mathrm{~m}$. O piso é trepidante e não regular, além de ser desprovido de piso tátil de alerta ou direcional. Em alguns trechos, essa circulação é invadida pela vegetação existente no local. A arquibancada não dispõe de espaços reservados às pessoas em cadeira de rodas, mobilidade reduzida, obesas e para acompanhantes dos deficientes (Figura 3).
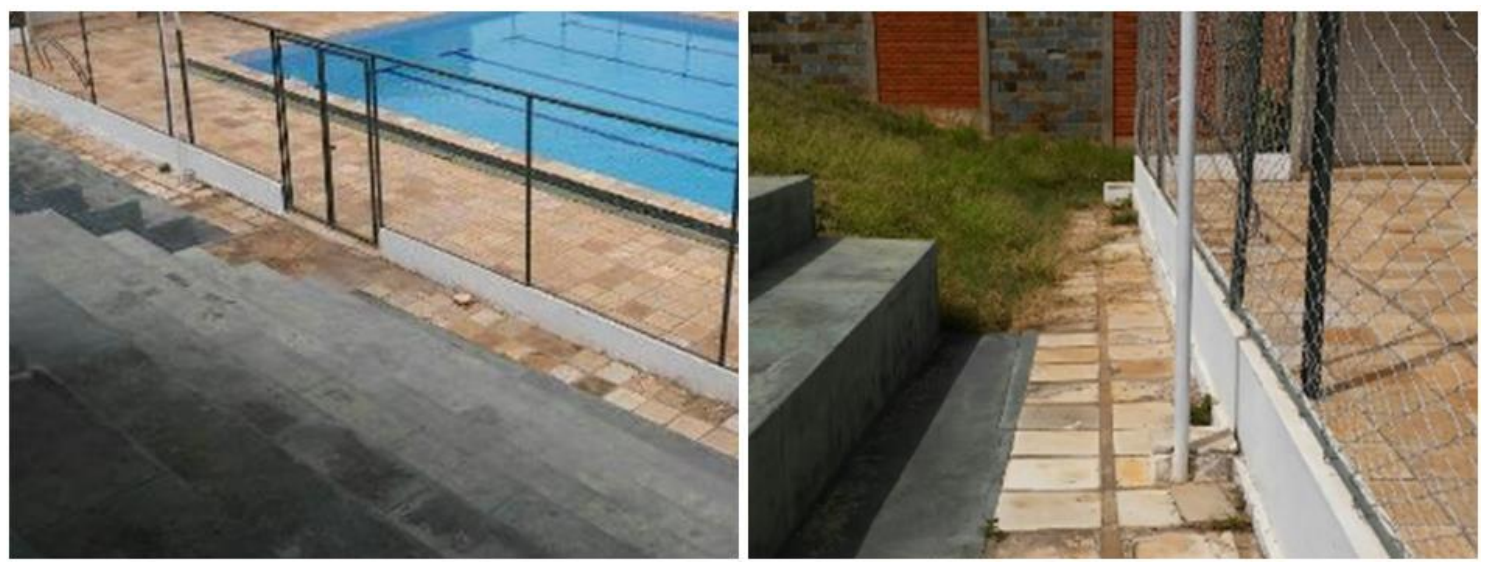

Figura 3 - Arquibancada e circulação de acesso, respectivamente Fonte: Autores (2017)

\subsection{Circulações}

A circulação interna do Parque Aquático é composta pelo mesmo piso da circulação externa. A área também não apresenta piso tátil direcional e alerta. No prédio, há uma área externa para banho, a qual não há rampas ou qualquer plano inclinado que possibilite o uso de forma acessível (Figura 4).

Quanto à piscina, não há acessibilidade para o seu uso, pois a mesma não possui recursos como degraus, rampas submersas, elevador aquático, bancos de transferência, etc (Figura 4). Em relação às áreas de acesso ao prédio, não há pisos de alerta que indiquem a presença de rampa de acesso.

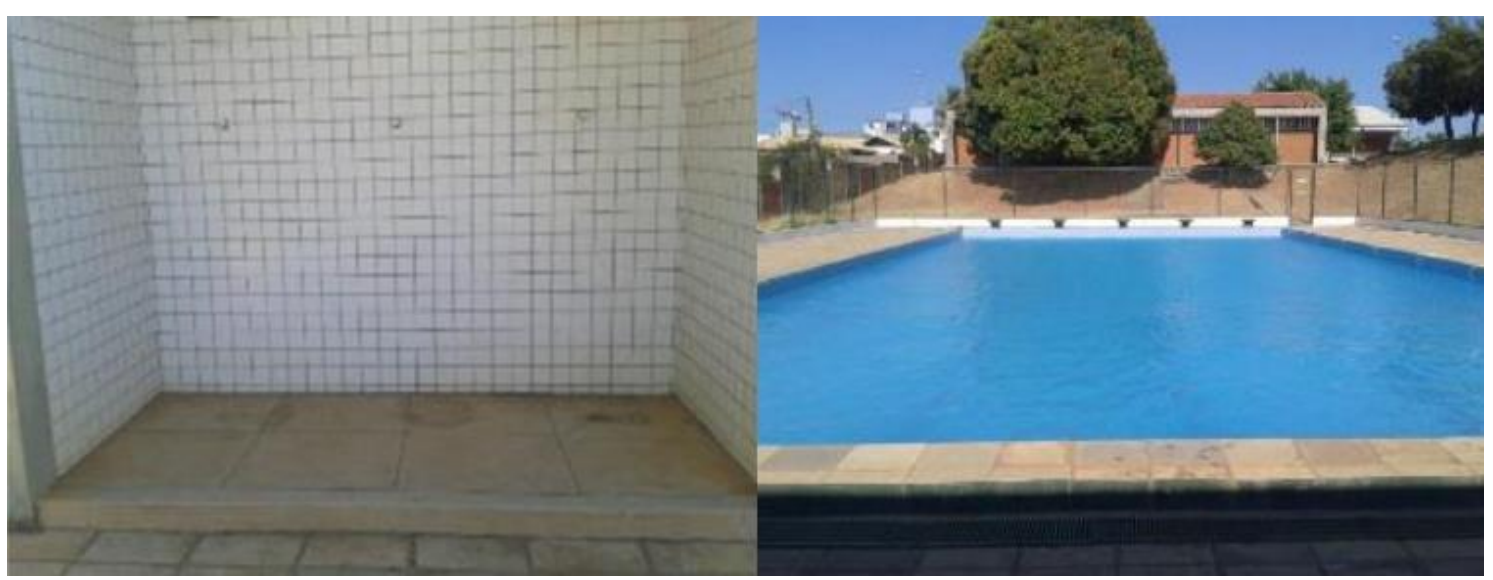

Figura 4 - Área externa para banho e piscina, respectivamente Fonte: Autores (2017)

A largura dos vãos de abertura das portas atende ao item 6.11.2.4, sendo de $0,90 \mathrm{~m}$ cada. Porém as portas não apresentam revestimento resistente a impactos (item 6.11.2.6), puxador horizontal associado à maçaneta e cor contrastante com a da parede e piso de forma a facilitar sua localização 
(item 6.11.2.7). A sinalização visual e tátil (Braille) está fora do intervalo de altura, conforme item 5.4.1, entre 1,20 m e 1,60 m (Figura 5).
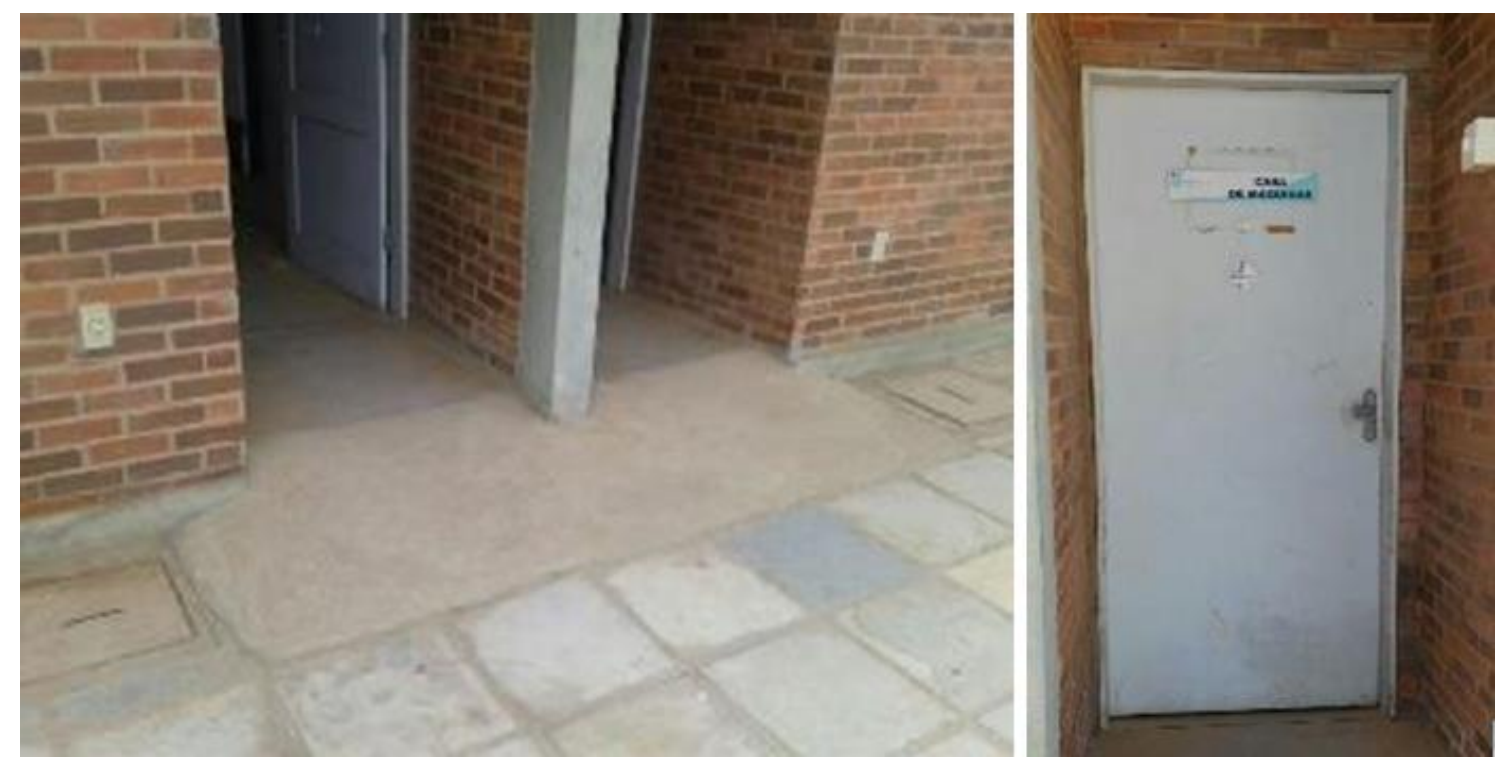

Figura 5 - Acesso aos vestiários e porta dos vestiários, respectivamente -

Fonte: Autores (2017)

\subsection{Mobiliários}

A largura dos vãos de abertura das portas atende ao item 6.1 1.2.4, sendo de $0,90 \mathrm{~m}$ cada. Porém as portas não apresentam revestimento resistente a impactos (item 6.11.2.6), puxador horizontal associado à maçaneta e cor contrastante com a da parede e piso de forma a facilitar sua localização (item 6.11.2.7). A sinalização visual e tátil (Braille) está fora do intervalo de altura, conforme item 5.4.1, entre 1,20 m e 1,60 m (Figura 5).

De acordo com o item 7.4.3, deve existir, pelo menos em cada vestiário, um box acessível com sanitário e chuveiro. Atualmente, há quatro boxes em cada vestiário (dois com sanitários e dois com chuveiros), porém nenhum possui qualquer elemento de acessibilidade.

Nos boxes com vaso sanitário não existem barras de apoio fixadas nas paredes, a porta não possui vão livre de $0,80 \mathrm{~m}$. Apesar do box do chuveiro respeitar as dimensões internas mínimas (item 7.12.1.2), tendo 0,97 x 1,40 m, não existe banco articulado ou removível para banho, o chuveiro não é equipado com ducha manual, não possui registro do tipo alavanca e o registro existente não está a $1 \mathrm{~m}$ do piso acabado e nem dista $0,45 \mathrm{~m}$ da parede em que foi fixado, como apresentado no item 7.14.1 (Figura 6).

Apesar do lavatório possuir altura frontal livre para área de aproximação e espaço para manobra do cadeirante, segundo o item 7.5, ele não possui dispositivo de acionamento por alavanca, sensor ou similares - item 4.6.7, e nem barras de apoio para auxílio na sua utilização, item 7.8 (Figura 6).

Percebe-se, pelos itens analisados, que diversos princípios do Desenho Universal não foram aplicados à concepção da edificação em estudo. Dos principais, se destacam: a falta de abrangência dos equipamentos e ambientes, não sendo possível a utilização dos mesmos por um grande número de pessoas (cadeirantes, obesos, idosos, etc); a ausência de seguridade nos acessos da edificação, caracterizada pela falta de corrimãos, 
guarda-corpo ou qualquer dispositivo semelhante e os obstáculos à obtenção de informação acerca do ambiente devido à ausência do sistema de piso tátil e da sinalização em Braille com altura inadequada.

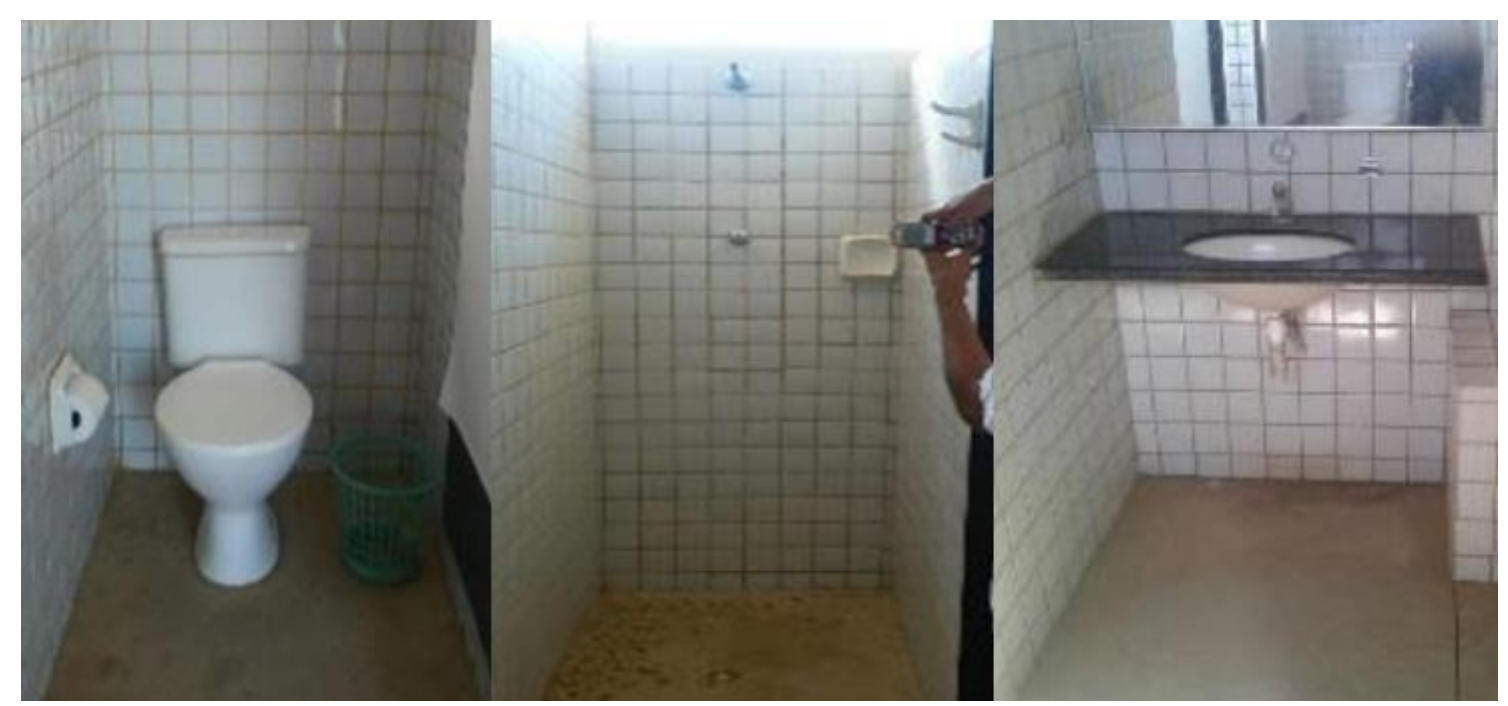

Figura 6 - Boxes com sanitários e chuveiro, respectivamente -

Fonte: Autores (2017)

Analisando as inconformidades apontadas por meio do checklist fundamentado nas normas técnicas de acessibilidade, foram elaboradas propostas de adequação física do ambiente em estudo, visando o menor impacto na infraestrutura existente, ou seja, propondo uma adequação arquitetônica com baixa intervenção de obras, o que aumenta as chances da execução pela Instituição.

Essas adequações foram resumidas em um Quadro de Soluções, apresentado a seguir. As soluções presentes no quadro foram ligadas diretamente com a proposta arquitetônica elaborada no projeto.

Além da adequação física proposta baseada nas normas de acessibilidade, a análise dos questionários fez com que se tornassem conhecidas demandas por parte dos deficientes físicos para uma adequação à nível institucional. As respostas dadas expuseram também obstáculos nas relações humanas e capacitação de profissionais para o trato com esse grupo de pessoas.

Percebe-se, ao analisar o Quadro 2, que a segurança e a autonomia do usuário no uso da edificação constituem uma demanda bastante válida. A ausência desses fatores traz uma inibição ao usuário quanto ao uso da edificação e suas instalações, seja para a prática esportiva ou socialização, e consequentemente usufruir dos seus benefícios.

O acompanhante dos deficientes, seja professor, intérprete ou cuidador, se mostrou um agente muito importante no processo de inclusão e socialização, sendo justificada a adoção de uma política de capacitação desses profissionais provinda da instituição de ensino.

Com o levantamento realizado no Parque Aquático, foi possível observar, registrar e confirmar as inconformidades que existem, de acordo com as recomendações da NBR 9050 (ABNT, 2015). 
Quadro 1 - Quadro de Soluções do Parque Aquático

\begin{tabular}{|c|c|c|c|}
\hline & Ambientes & Incompatibilidades & $\begin{array}{l}\text { Adequações } \\
\text { Arquitetônicas }\end{array}$ \\
\hline A & Estacionamento & $\begin{array}{c}\text { Ausência de vagas e sinalização para } \\
\text { deficientes }\end{array}$ & $\begin{array}{l}\text { Demarcar horizontal e } \\
\text { verticalmente as vagas } \\
\text { preferenciais }\end{array}$ \\
\hline B & $\begin{array}{l}\text { Acessos ao Parque } \\
\text { Aquático }\end{array}$ & $\begin{array}{l}\text { Rampa com elevado grau de } \\
\text { deterioração, declividade } \\
\text { inadequada, sem guarda-corpo, } \\
\text { corrimãos e guias de balizamento }\end{array}$ & Adequação da rampa \\
\hline C & Circulações externas & Piso trepidante e irregular & $\begin{array}{l}\text { Uniformizar o piso, porém } \\
\text { mantendo-o } \\
\text { antiderrapante e } \\
\text { utilizando uma pedra fria }\end{array}$ \\
\hline D & Arquibancadas & Altura não acessível & $\begin{array}{c}\text { Determinar espaços } \\
\text { reservados para PCR, PO e } \\
\text { seus acompanhantes }\end{array}$ \\
\hline E & $\begin{array}{l}\text { Circulação na área } \\
\text { da piscina }\end{array}$ & Orientação da grelha inadequada & Adequação da Grelha \\
\hline $\mathrm{F}$ & $\begin{array}{l}\text { Acesso à área de } \\
\text { banho externa }\end{array}$ & $\begin{array}{c}\text { Desnível e sem equipamentos } \\
\text { acessíveis }\end{array}$ & $\begin{array}{c}\text { Retirada do desnível e } \\
\text { instalação dos } \\
\text { equipamentos para área } \\
\text { de banho (bancos, barras, } \\
\text { etc.) }\end{array}$ \\
\hline G & Acesso à piscina & Falta de acesso & $\begin{array}{l}\text { Instalação de um } \\
\text { elevador aquático }\end{array}$ \\
\hline $\mathrm{H}$ & Portas dos vestiários & $\begin{array}{c}\text { Sem revestimento a impactos, } \\
\text { puxador horizontal e sinalizações } \\
\text { visual e tátil }\end{array}$ & $\begin{array}{l}\text { Instalar revestimento } \\
\text { resistente a impactos, } \\
\text { puxador horizontal e } \\
\text { sinalização visual e tátil }\end{array}$ \\
\hline I & Demais portas & Sem sinalizações visual e tátil & $\begin{array}{c}\text { Instalar sinalizações visual } \\
\text { e tátil }\end{array}$ \\
\hline \multirow{3}{*}{ J } & \multirow{3}{*}{ Box com sanitário } & Vão livre de acesso inferior a $80 \mathrm{~cm}$ & $\begin{array}{l}\text { Aumentar as dimensões } \\
\text { de acesso ao box }\end{array}$ \\
\hline & & Ausência de barras de apoio & $\begin{array}{c}\text { Instalação de barras de } \\
\text { apoio }\end{array}$ \\
\hline & & $\begin{array}{l}\text { Ausência de equipamentos } \\
\text { (papeleiro, lixeiro, etc.) }\end{array}$ & Instalar equipamentos \\
\hline \multirow{3}{*}{ K } & \multirow{3}{*}{ Box com chuveiro } & $\begin{array}{c}\text { Ausência de barras de apoio e } \\
\text { banco articulado ou fixo }\end{array}$ & $\begin{array}{l}\text { Instalação de barras de } \\
\text { apoio e banco articulado }\end{array}$ \\
\hline & & Acionamento não adequado & $\begin{array}{l}\text { Substituir acionamento do } \\
\text { lavatório }\end{array}$ \\
\hline & & $\begin{array}{l}\text { Ausência de equipamentos } \\
\text { (toalheiro, saboneteira, etc.) }\end{array}$ & Instalar equipamentos \\
\hline \multirow{3}{*}{ L } & \multirow{3}{*}{ Lavatório } & Acionamento inadequado & Substituir acionamento \\
\hline & & Ausência de barras de apoio & $\begin{array}{c}\text { Instalação de barras de } \\
\text { apoio }\end{array}$ \\
\hline & & $\begin{array}{l}\text { Ausência de equipamentos } \\
\text { (toalheiro, saboneteira, etc.) }\end{array}$ & Instalar equipamentos \\
\hline
\end{tabular}

Fonte: Elaborado pelos autores

As áreas de estacionamento, apesar de estarem localizadas sobre um piso estável, não possuem nenhuma vaga reservada para deficientes ou pessoas 
idosas, enquanto o ideal seria uma proporção de $2 \%$ das vagas, com um no mínimo, para pessoas com deficiência e mobilidade reduzida e $5 \%$ das vagas, com um no mínimo, para idosos, segundo a NBR 9050 (ABNT, 2015).

Os acessos às áreas esportivas são de difícil circulação e escassos, seja por elementos de circulação vertical mal projetados ou deteriorados com o tempo, ou pela má sinalização dos percursos.

As arquibancadas são totalmente inacessíveis, pela elevada altura e ausência de espaços destinados às cadeiras de rodas, nem mesmo assentos destinados às pessoas obesas ou com mobilidade reduzida e seus acompanhantes.

Em relação aos vestiários e banheiros não existe nenhum box acessível, indo de encontro à NBR 9050 (ABNT, 2015), que recomenda 5\% do total de boxes acessíveis.

\section{Quadro 2 - Quadro de Interpretação das Entrevistas}

\begin{tabular}{|c|c|c|}
\hline Respostas & Propostas & Observações \\
\hline $\begin{array}{l}\text { Circulações verticais sem } \\
\text { elementos de segurança }\end{array}$ & $\begin{array}{l}\text { Instalação de corrimãos, guarda- } \\
\text { corpos e peitoris adequados }\end{array}$ & $\begin{array}{c}\text { Garantir a segurança dos } \\
\text { usuários }\end{array}$ \\
\hline $\begin{array}{c}\text { Permitir a circulação livre } \\
\text { e segura em todos os } \\
\text { ambientes }\end{array}$ & $\begin{array}{c}\text { Circulações, externa e interna, } \\
\text { acessiveis (rampas, espaços } \\
\text { mínimos para circulação e } \\
\text { manobra) }\end{array}$ & Autonomia para circulação \\
\hline Permitir acesso à piscina & Elevador Aquático & $\begin{array}{c}\text { Acesso à piscina sem reforma } \\
\text { ou alteração da estrutura } \\
\text { física existente }\end{array}$ \\
\hline $\begin{array}{l}\text { Permitir o uso dos } \\
\text { vestiários }\end{array}$ & Vestiários acessíveis & $\begin{array}{c}\text { Acesso à box com sanitário e } \\
\text { box com chuveiro }\end{array}$ \\
\hline Arquibancadas altas & $\begin{array}{l}\text { Tornar as arquibancadas } \\
\text { devidamente acessíveis }\end{array}$ & $\begin{array}{c}\text { Destinar espaços adequados } \\
\text { pra deficientes, obesas e seus } \\
\text { acompanhantes }\end{array}$ \\
\hline \multirow[b]{2}{*}{$\begin{array}{l}\text { Preparar os profissionais } \\
\text { da Instituição }\end{array}$} & Sala para os Educadores Físicos & $\begin{array}{c}\text { Área destinada ao } \\
\text { planejamento das atividades } \\
\text { profissionais }\end{array}$ \\
\hline & $\begin{array}{c}\text { Capacitação dos profissionais } \\
\text { (professores, intérpretes e } \\
\text { cuidadores) }\end{array}$ & $\begin{array}{c}\text { Cursos que forneçam } \\
\text { condições para que esses } \\
\text { profissionais acompanhem os } \\
\text { deficientes nas atividades } \\
\text { esportivas }\end{array}$ \\
\hline $\begin{array}{l}\text { Falta de profissionais } \\
\text { específicos, como } \\
\text { fisioterapeuta }\end{array}$ & $\begin{array}{l}\text { Parceria com outros profissionais } \\
\text { e/ou Instituições }\end{array}$ & $\begin{array}{c}\text { Utilizar esses ambientes como } \\
\text { espaços de recuperação, } \\
\text { tratamento, sociabilização e } \\
\text { integração }\end{array}$ \\
\hline
\end{tabular}

Fonte: Elaborado pelos autores

\section{CONCLUSÕES}

De acordo com o diagnóstico obtido mediante a aplicação da Avaliação Pós-ocupação, o Parque Aquático possui muitas inconformidades com a norma referência em acessibilidade, NBR 9050 (ABNT, 2015), dificultando a prática de esportes e/ou até mesmo o acesso de pessoas deficientes.

A avaliação conduzida concluiu que o Parque Aquático é parcialmente inacessível, visto que este não possui uma rota segura que possa guiar tanto 
cadeirantes quanto deficientes visuais para seu interior devido ao desnível acentuado, falta de rampas e inexistência de piso de sinalização tátil, horizontais ou verticais.

Conclui-se também que o ambiente não dispõe de rota de fuga acessível, em caso de emergência, além de possuir pisos trepidantes (desconfortáveis para usuários portadores de cadeira de rodas). No interior do ambiente, pôde-se observar que os banheiros não são acessíveis, visto que o acesso é bastante complicado devido à existência de barreiras; não existe piso tátil para guiar deficientes, tampouco vagas nas arquibancadas destinadas para obesos e cadeirantes. Vale ressaltar que o Parque ainda não dispõe vagas de estacionamentos para atender deficientes físicos.

Com o aumento no número de pessoas deficientes e da participação e contribuição social destes, faz-se necessário uma discussão cada vez mais presente na sociedade sobre a necessidade da acessibilidade nas edificações, permitindo efetivamente o real acesso, utilização e autonomia dos espaços por todos. Sendo assim, a necessidade de acessibilidade em ambientes esportivos é real e necessária, pois o ambiente institucional de ensino deve ser observado como parâmetro de referência para a manutenção concreta e duradoura no fortalecimento de laços sociais entre todos os indivíduos que a compõe.

\section{AGRADECIMENTOS}

Ao IFPB pelo suporte financeiro para o desenvolvimento desta pesquisa.

\section{REFERÊNCIAS}

ASSOCIAÇÃO BRASILEIRA DE NORMAS TÉCNICAS (ABNT). NBR 9050:

Acessibilidade a edificações, mobiliário, espaços e equipamentos urbanos. Rio de janeiro, 2015.

NBR 9077: Saídas de emergência em edifícios. Rio de Janeiro, 2001.

BARROZO, F. B. et al. Acessibilidade ao esporte, cultura e lazer para pessoas com deficiência. Cadernos de Pós-Graduação em Distúrbios do

Desenvolvimento, São Paulo, v.12, n.2, P. 16-28, 2012.

BRASIL. Lei n..$^{\circ}$ 13146, de 06 de julho de 2015. Institui a Lei Brasileira de Inclusão da Pessoa com Deficiência (Estatuto da Pessoa com Deficiência). Disponível em: <http://wWw.planalto.gov.br/ccivil_03/_Ato2015-

2018/2015/Lei/L13146.htm>. Acesso em: 03 jan. 2018.

CARLETTO, A. C.; CAMBIAGHI, S. Desenho Universal: um conceito para todos. São Paulo: Instituto Mara Gabrilli, 2007.

CORDEIRO, T. P. Ambiente e acessibilidade para pessoas com deficiência no desenvolvimento de atividades esportivas em piscinas: um estudo de casos.

2010. 167f. Dissertação (Mestrado em Ambiente e Desenvolvimento) - Centro Universitário Univates, Lajeado, 2010. Disponível em:

<https://www.univates.br/bdu/bitstream/10737/105/1/TaisCordeiro.pdf>.

Acesso em: 02 jan. 2018.

FEDERAL FACILITIES COUNCIL. Learning from Our Buildings - a state of the practice summary of post-occupancy evaluation. Washington, DC: National 
Academy Press, 2001. (Federal Facilities Council Technical Report n. 145). Disponível em: <https://www.nap.edu/catalog/10288/learning-from-ourbuildings-a-state-of-the-practice-summary:>. Acesso em: 02 jan. 2018.

MARCONI, M. A.; LAKATOS, E. M. Metodologia científica. 4 ed. São Paulo: Atlas, 2004. 305p.

MINISTÉRIO PÚBLICO DO RIO GRANDE DO NORTE (MP/RN). Acessibilidade: projetando e construindo cidadania. Cartilha de Bolso, Natal, 2010.

ORNSTEIN, S. W. Avaliação pós-ocupação (apo) no brasil, 30 anos: o que há de novo? Revista Projetar - Projeto e Percepção do Ambiente, v.2, n.2, p. 7-12,

Ago. 2017. Disponível em:

<https://periodicos.ufrn.br/revprojetar/article/download/16580/1 1038/>.

Acesso em: 07 jan. 2018.

PREISER, W. F. E. Post-occupancy evaluation: how to make buildings work better. Facilities, v. 13, p. 19-28, Issue: 11, 1995.

https://doi.org/10.1 108/02632779510097787

SOUZA, S.C.; POST, A.P.D. Universal Design: An Urgent Need. Procedia - Social and Behavioral Sciences, v. 216 , Pages 338-344, 2016. ISSN 1877-0428.

https://doi.org/10.1016/j.sbspro.2015.12.046.

ZUCHETTO, A. T.; CASTRO, R. L. V. G. As contribuições das atividades físicas para a qualidade de vida dos deficientes físicos. Revista Kinesis, Santa Maria, n. 26, p. 52-166, 2002. 